\title{
Supporting Information for: Transition State Analysis of Model and Enzymatic Prenylation Reactions
}

Stepan Lenevich, Juhua Xu, Ayako Hosokawa, Christopher J. Cramer and Mark D. Distefano

Department of Chemistry, University of Minnesota, 207 Pleasant Street SE, Minneapolis, MN 55455.

distefan@chem.umn.edu

Table of Contents

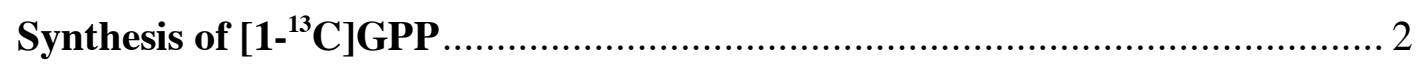

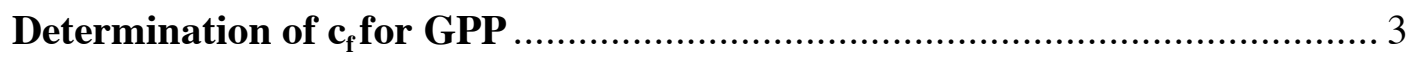

Enzymatic Reactions and KIE Determination ......................................... 7

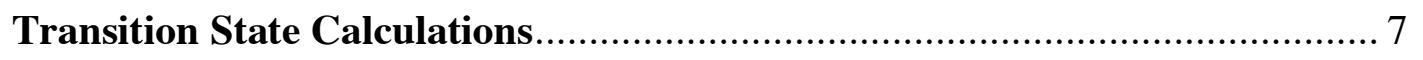

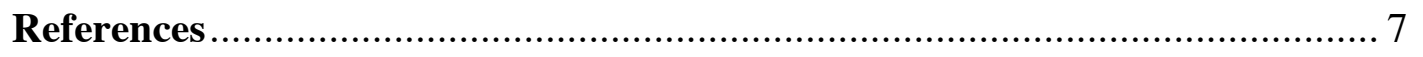




\section{Synthesis of $\left[1-{ }^{13} \mathrm{C}\right] \mathrm{GPP}$}

General. Analytical TLC was performed on precoated $(250 \mu \mathrm{m})$ silica gel $60 \mathrm{~F}-245$ plates from Merck and the developed plates were visualized by UV irradiation or staining with $\mathrm{KMnO}_{4}$ or with phosphomolybdic acid (PMA). Flash chromatography silica gel (60-120 mesh) was obtained from Mallinckrodt Inc. $\mathrm{CH}_{2} \mathrm{Cl}_{2}$, THF, and $\mathrm{CH}_{3} \mathrm{CN}$ were dried using a $\mathrm{M}$. Braun solvent purification system. Deuterated MNR solvents were used as obtained from Cambridge Isotope Laboratories Inc. [1- $\left.{ }^{13} \mathrm{C}\right]-$ Triethylphosphonoacetate was obtained from Aldrich Chemical Company. ${ }^{1} \mathrm{H}-\mathrm{NMR}$ spectra were acquired at 200 or $300 \mathrm{MHz},{ }^{13} \mathrm{C}-\mathrm{NMR}$ spectra were obtained at $75 \mathrm{MHz}$. and ${ }^{31} \mathrm{P}-\mathrm{NMR}$ spectra were obtained at $121 \mathrm{MHz}$; all NMR spectra were obtained on Varian instruments at $25^{\circ} \mathrm{C}$. Chemical shifts are reported in ppm and $J$ values are given in Hz. Preparative HPLC was carried out using a Beckman instrument with a UV detector $(214 \mathrm{~nm})$ and was performed using a Phenomenex $\mathrm{C}_{18}$ column (Luna 10 $\mu \mathrm{m}, 100 \AA, 250 \times 10 \mathrm{~mm}$ ).

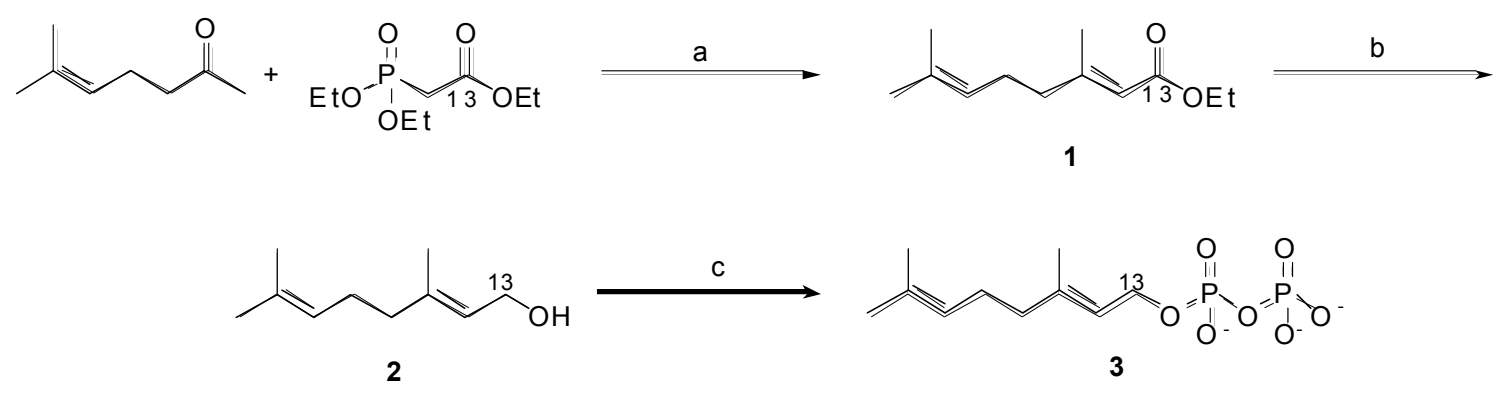

Figure S1. a: $n$-BuLi, THF, $-60{ }^{\circ} \mathrm{C}$; b: $i$ - $\mathrm{Bu}_{2} \mathrm{AlH}, \mathrm{PhCH}_{3} /$ hexanes, $-70{ }^{\circ} \mathrm{C} ; \mathrm{c}: \mathrm{CBr}_{4}, \mathrm{Ph}_{3} \mathrm{P}$ (polymer supported), $\mathrm{CH}_{2} \mathrm{Cl}_{2}$, then $\left[(n-\mathrm{Bu})_{4} \mathrm{~N}\right]_{3} \mathrm{P}_{2} \mathrm{O}_{7} \mathrm{H}, \mathrm{CH}_{3} \mathrm{CN}$.

Introductory Comments. Compound $\left[1-{ }^{13} \mathrm{C}\right]-3\left(\left[1-{ }^{13} \mathrm{C}\right]-\mathrm{GPP}\right)$ was prepared using the procedure previously described by Gibbs and coworkers. ${ }^{1}$

Ethyl [1- $\left.{ }^{13} \mathrm{C}\right]-3,7-\operatorname{dimethyl-2}(\boldsymbol{E}), 6$-octadienoate $\left(\left[1-{ }^{13} \mathrm{C}\right]-1\right) .\left[1-{ }^{13} \mathrm{C}\right]$-Triethylphosphonoacetate $(1.0$ $\mathrm{g}, 4.5 \mathrm{mmol})$ in THF $(10 \mathrm{~mL})$ under argon was metallated at $-60^{\circ} \mathrm{C}$, by addition via syringe, of a slight excess of a $n$-BuLi solution in hexanes $(2.5 \mathrm{M}, 1.9 \mathrm{~mL}, 4.7 \mathrm{mmol})$ over $5 \mathrm{~min}$. The mixture was maintained at $-60{ }^{\circ} \mathrm{C}$ for $20 \mathrm{~min}$. A solution of 6-methyl-5-hepten-2-one $(0.57 \mathrm{~g}, 4.5 \mathrm{mmol})$ in THF (2.0 $\mathrm{mL}$ ) was cooled to $-20{ }^{\circ} \mathrm{C}$, added in one portion to the slightly yellow solution of the lithiated phosphonoacetate, and the resulting mixture was stirred for $20 \mathrm{~h}$ at room temperature, after which time it was orange-red in color. The reaction mixture was quenched with saturated $\mathrm{NH}_{4} \mathrm{Cl}$, the aqueous phase was extracted with $\mathrm{Et}_{2} \mathrm{O}(3 \times 10 \mathrm{~mL})$, the combined organic layers were dried with $\mathrm{Na}_{2} \mathrm{SO}_{4}$ and the solvents were removed in vacuo. The crude material was purified by flash chromatography (silica gel, hexanes/EtOAc, 8:1, v/v) to yield $0.73 \mathrm{~g}(83 \%)$ of a colorless oil.

[1- $\left.{ }^{13} \mathrm{C}\right]-3,7-d i m e t h y l-2(E), 6-o c t a d i e n o l ~\left(\left[1-{ }^{13} \mathrm{C}\right]-2\right)$. Diisobutylaluminium hydride in toluene (1.5 M, $8.0 \mathrm{~mL}, 12 \mathrm{mmol})$ was added via syringe over $5 \mathrm{~min}$ at $-70{ }^{\circ} \mathrm{C}$ to a solution of ethyl $\left[1-{ }^{13} \mathrm{C}\right] 3,7$-dimethyl2,6-octadienoate $(1,0.73 \mathrm{~g}, 3.5 \mathrm{mmol})$ in hexane $(20 \mathrm{~mL})$. After the addition was complete, the cooling bath was removed and the reaction was stirred at $\mathrm{rt}$ for $1 \mathrm{~h}$ at which time TLC indicated the reaction was complete. The mixture was cooled to $0{ }^{\circ} \mathrm{C}$ using an ice bath and water was added very slowly (to quench excess reducing agent) until evolution of gas had ceased. The resulting suspension was filtered, the solid was washed with EtOAc, and the combined organic fractions were dried by treatment with $\mathrm{Na}_{2} \mathrm{SO}_{4}$, followed by evaporation in vacuo. Purification of the crude oily residue by flash chromatography yielded $500 \mathrm{mg}$ of pure product $(88 \%)$ as a colorless oil. 
$\left[1-^{13} \mathbf{C}\right]-3,7-d i m e t h y l-2(E), 6-o c t a d i e n-1-y l ~ d i p h o s p h a t e ~\left(\left[1-{ }^{13} \mathbf{C}\right]-3\right) . \quad(E)-\left[1-{ }^{13} \mathrm{C}\right]-3,7-$ dimethyl-2,6octadienol (2, $38 \mathrm{mg}, 0.25 \mathrm{mmol}$ ), $\mathrm{PPh}_{3}$ (on polymer-support) $84 \mathrm{mg}$ (2 eq) and $\mathrm{CH}_{2} \mathrm{Cl}_{2}$ were combined and allowed to stirred for $30 \mathrm{~min}$ at $\mathrm{rt}$ at which time $\mathrm{CBr}_{4}(100 \mathrm{mg}, 0.35 \mathrm{mmol})$ was added. The resulting reaction mixture was stirred for $4 \mathrm{~h}$ followed by filtration to remove the polymer-supported $\mathrm{PPh}_{3}$. Rotary evaporation of the solution yielded crude product (geranyl bromide) that was used without further purification. The crude bromide was dissolved in $\mathrm{CH}_{3} \mathrm{CN}(2.0 \mathrm{~mL}),\left[(n-\mathrm{Bu})_{4} \mathrm{~N}\right]_{3} \mathrm{P}_{2} \mathrm{O}_{7} \mathrm{H}(450 \mathrm{mg})$ was added, and stirred at $\mathrm{rt}$ for $2 \mathrm{~h}$; evaporation of the solvent in vacuo gave a white solid which was dissolved in $5.0 \mathrm{~mL}$ of a solution of $i$-PrOH and $25 \mathrm{mM} \mathrm{NH}_{4} \mathrm{HCO}_{3}$ (1:49), and applied to an ion exchange column equilibrated in the same solvent. Elution with more of the same solvent gave the crude product as the ammonium salt. Final purification was performed by reversed phase HPLC (buffer A: $25 \mathrm{mM} \mathrm{NH} \mathrm{HCO}_{3}$; buffer B: $\mathrm{CH}_{3} \mathrm{CN}$; flow rate: $5.0 \mathrm{~mL} / \mathrm{min}$; gradient rate: $1 \%$ increase in buffer $\mathrm{B} / \mathrm{min})$. Fractions containing the desired product $\left(\mathrm{t}_{\mathrm{R}}=13 \mathrm{~min}\right)$ were lyophilized to give $25 \mathrm{mg}(27 \%$ yield). ${ }^{1} \mathrm{H}-\mathrm{NMR}\left(\mathrm{D}_{2} \mathrm{O}, 300 \mathrm{MHz}\right) 5.31(\mathrm{t}, \mathrm{J}=6.9 \mathrm{~Hz}, 1 \mathrm{H}), 5.06(\mathrm{t}, \mathrm{J}=6.8 \mathrm{~Hz}, 1 \mathrm{H}), 4.59(\mathrm{~m}, 1 \mathrm{H}), 4.09(\mathrm{t}$, $\mathrm{J}=6.6 \mathrm{~Hz}, 1 \mathrm{H}), 1.98(\mathrm{~m}, 4 \mathrm{H}), 1.57(\mathrm{~s}, 3 \mathrm{H}), 1.54(\mathrm{~s}, 3 \mathrm{H}), 1.48(\mathrm{~s}, 3 \mathrm{H}) ;{ }^{31} \mathrm{P}-\mathrm{NMR}\left(\mathrm{D}_{2} \mathrm{O}, 121 \mathrm{MHz}\right)-9.8(\mathrm{~d}$, $\mathrm{J}=20.1 \mathrm{~Hz}, 1 \mathrm{P}),-10.3(\mathrm{~d}, \mathrm{~J}=20.1 \mathrm{~Hz}, 1 \mathrm{P})$; HRMS (TOF, negative ion mode): $[\mathrm{M}-\mathrm{H}]^{-}$calcd for $\mathrm{C}_{9}{ }^{13} \mathrm{CH}_{20} \mathrm{O}_{7} \mathrm{P}_{2}$ 314.0612; found: 314.0586 .

\section{Determination of $c_{f}$ for FPP and GPP ${ }^{2}$}

General. Yeast farnesyltransferase ( $y$ PFTase) was purified from E.coli DH5 $\alpha / \mathrm{pGP} 114$ as previously described. The concentration and specific activity of this enzyme were $11 \mu \mathrm{M}$ and $0.867 \mu \mathrm{mol} / \mathrm{min} / \mathrm{mg}$, respectively. $\left[{ }^{3} \mathrm{H}\right]$-FPP and $\left[{ }^{3} \mathrm{H}\right]$-GPP were both purchased from American Radiolabeled Chemicals Inc. Phosphocellulose P 81 chromatography membranes were purchased from Whatman. Radioactivity measurements were performed using a Beckman model LS 3801 Scintillation Counter.

Isotopic Trapping Experimental Method. Trapping of the radiolabeled intermediate complex $\left(E \cdot S^{*}\right)$ was performed by following the method described by Mathis and Poulter. ${ }^{3}$ A pulse solution containing $y$ PFTase $(1.4 \mu \mathrm{M})$ and $\left[{ }^{3} \mathrm{H}\right]-\mathrm{FPP}(200 \mathrm{nM}, 1000 \mu \mathrm{Ci} / \mu \mathrm{mol})$ was diluted to $50 \mu \mathrm{L}$ using a reaction buffer (50 mM Tris $\cdot \mathrm{HCl}, \mathrm{pH} 7.5,10 \mathrm{mM} \mathrm{MgCl} 2,10 \mu \mathrm{M} \mathrm{ZnCl}_{2}, 5.0 \mathrm{mM}$ DTT, and $0.040 \%$ $(w / v) n$-dodecyl- $\beta$-D-maltoside) and one half of the total volume $(25 \mu \mathrm{L})$ was transferred to be preincubated at $30{ }^{\circ} \mathrm{C}$ for $10 \mathrm{~min}$. RTRCVIA peptide solution $(0.1-5 \mu \mathrm{M}$ for FPP experiments; $10-100$ $\mu \mathrm{M}$ for GPP experiments) and unlabeled FPP $(70 \mu \mathrm{M})$ were also mixed to make $50 \mu \mathrm{L}$ of chase solutions and pre-incubated. The chase solution $(25 \mu \mathrm{L})$ was added to the pre-equilibrated pulse solution $(25 \mu \mathrm{L}$ ) to yield $50 \mu \mathrm{L}$ (total volume) and vortexed for 8-10 s. The reaction mixture was placed on ice, quenched by the addition of $\mathrm{HCl}(10 \mu \mathrm{L}, 1.2 \mathrm{M}$ stock solution), and mixed by pipetting up and down. The reaction mixture was analyzed by pipetting half of the quenched reaction $(30 \mu \mathrm{L})$ onto a $1.25 \mathrm{~cm}$ diameter of phosphocellulose P 81 chromatography membrane. Following a few seconds for

the liquid to enter the paper, the membrane was treated with a wash solution $(10 \mathrm{~mL}, 75 \mathrm{mM}$ $\mathrm{H}_{3} \mathrm{PO}_{4} / 95 \%$ ethanol $(50: 50, \mathrm{v} / \mathrm{v})$ stock solution) for 10 min with mild shaking on a rotary shaker to remove any unincorporated $S$, which was not bound specifically to the membrane. The retained radioactivity was quantified by placing the membrane in a scintillation vial with Cytoscint $(5 \mathrm{~mL})$ and 6 $\mathrm{M} \mathrm{HCl}(250 \mu \mathrm{L})$. Accurate radioactivity measurements were obtained by placing the scintillation vials containing membranes inside the scintillation counter for $5 \mathrm{~h}$ after the reaction mixture was quenched and prior to determining the amount of radioactivity. The second half of the pulse solution $(25 \mu \mathrm{L})$ with the enzyme component replaced with reaction buffer was added to the chase solution $(25 \mu \mathrm{L})$ and used as a background which was subtracted from assay measurements.

Determination of commitment coefficient for FPP and GPP using isotope trapping experiments. In isotope trapping experiments, the commitment coefficient $\left(K_{1 / 2}\right)$, is defined as the 
concentration of peptide needed to convert half of the binary enzyme-complex to product, and can be determined using a non-linear regression fit of Equation S1 based on the Cleland's partition theory ${ }^{4}$

$$
\left[S *-P e p_{o b s}\right]=\frac{E \cdot S_{0}[P e p]}{K_{1 / 2}+[P e p]} \quad(\text { Eq. S1) }
$$

$S^{*}-P e p_{o b s}$ is the concentration of radiolabeled product, $E \cdot S_{0}$ is the concentration of enzyme-bound phosphate substrate (binary complex), and Pep is the concentration of peptide in the mixture of pulse and chase solutions.

Mathis and Poulter have previously used the isotope trapping method by employing an ion-exchange chromatography method to efficiently separate the radiolabeled, farnesylated product from the unreacted, radiolabeled isoprenoid substrate based on the positively charged peptide, RTRCVIA $(P e p) .^{3}$ In brief, a pulse solution containing $y$ PFTase $(E)$ and radiolabeled diphosphate substrate $\left(S^{*}\right)$ to form an $E \cdot S^{*}$ binary complex at equilibrium is first prepared. Yeast PFTase was used for this experiment because of its lower binding affinity to FPP relative to human PFTase. The chase solution, containing peptide substrate, Pep (final concentration: 0-2.5 $\mu \mathrm{M}$ for FPP and 0-50 $\mu \mathrm{M}$ for GPP) and unlabeled first substrate $(S)$, is quickly mixed with this pre-incubated solution. In the presence of the second substrate, the binary complex can either form a ternary complex $\left(E \cdot S^{*} \cdot P e p\right)$ that eventually converts to product $\left(S^{*}\right.$ $\left.P e p_{o b s}\right)$, or dissociate to release free radiolabeled substrate $\left(S^{*}\right)$. The enzyme released from the binary complex will subsequently bind with unlabeled substrate $(S)$ due to its presence in large excess in a chase solution. The reaction mixture is quenched by addition of acid on ice and applied to P81 filter paper. Phosphocellulose P81 functions as a strong cation exchanger, allowing only product $\left(S^{*}-P e p_{o b s}\right)$ containing the positively charged peptide (RTRCVIA) to bind, but not the free isoprenoid $(S)$ that has no peptide associated with it. After treatment with a wash solution, the radioactivity on the P81 membrane is quantified using liquid scintillation counting, which can be used to calculate the amount of product $\left(S^{*}-P e p_{o b s}\right)$.

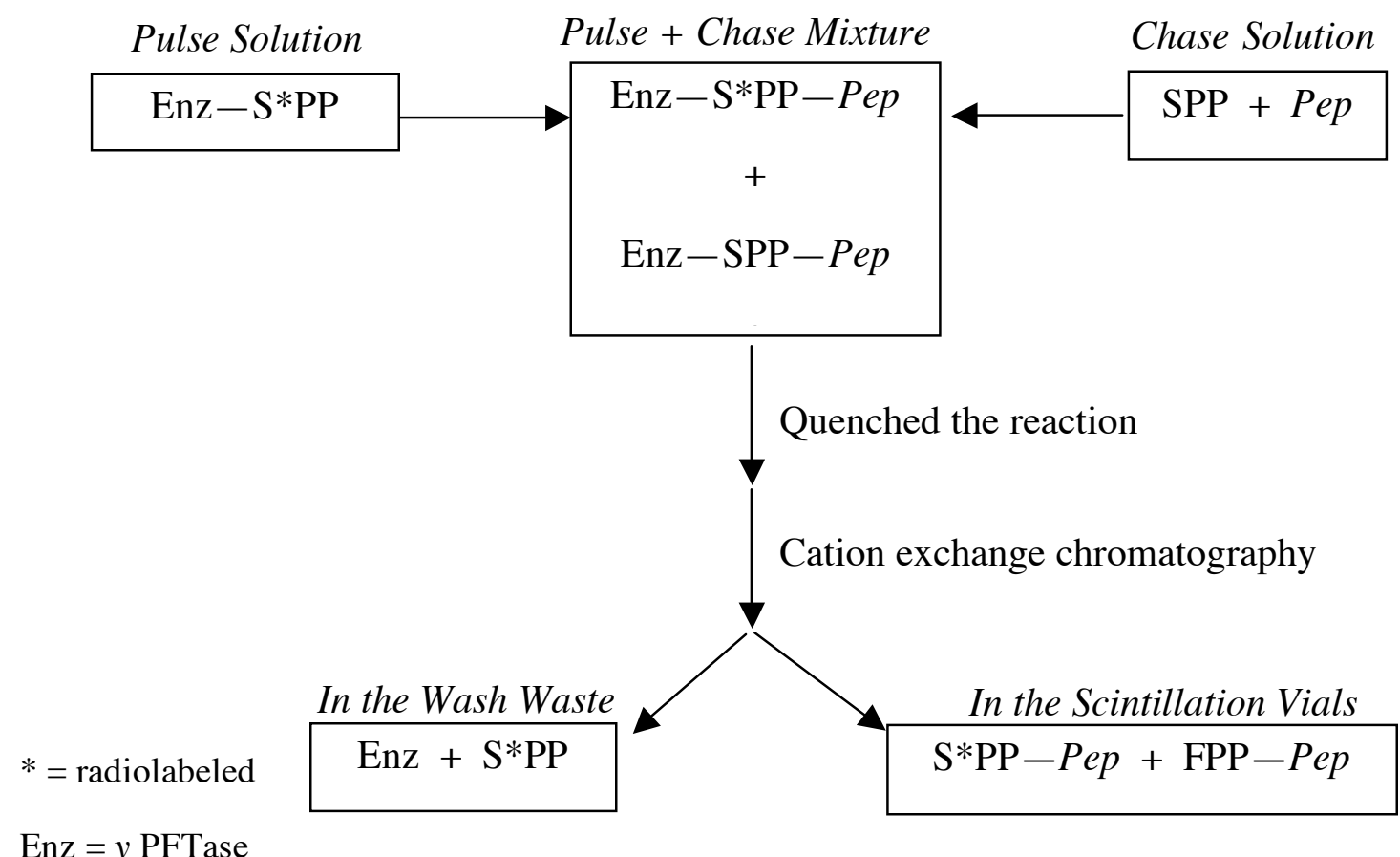

Figure S2. Brief schematic procedure of isotope trapping experiment. 
Initial studies repeated Poulter's experiment using labeled FPP as the isoprenoid diphosphate substrate $\left(S^{*}\right)$ along with unlabeled FPP as a chasing isoprenoid. The data points at 6 different peptide concentrations were fit to Equation $\mathrm{S} 1$ to yield $K_{1 / 2}$ of $1.1 \mu \mathrm{M}$ and $\left[E \cdot F P P_{0}\right]$ of $43.5 \mathrm{nM}$ (Figure S3). These results suggest that the $E \cdot S^{*}$ complex binds tightly to $P e p$ and rapidly forms a product with significant commitment. A forward commitment factor $\left(\mathrm{c}_{f}\right)$ of 0.38 was determined for FPP using Equation S2 and the value of $K_{M}$ for FPP reported (Table S1). ${ }^{3}$

$$
c_{f}=\frac{K_{M}}{K_{1 / 2}} \quad \text { (Eq. S2) }
$$

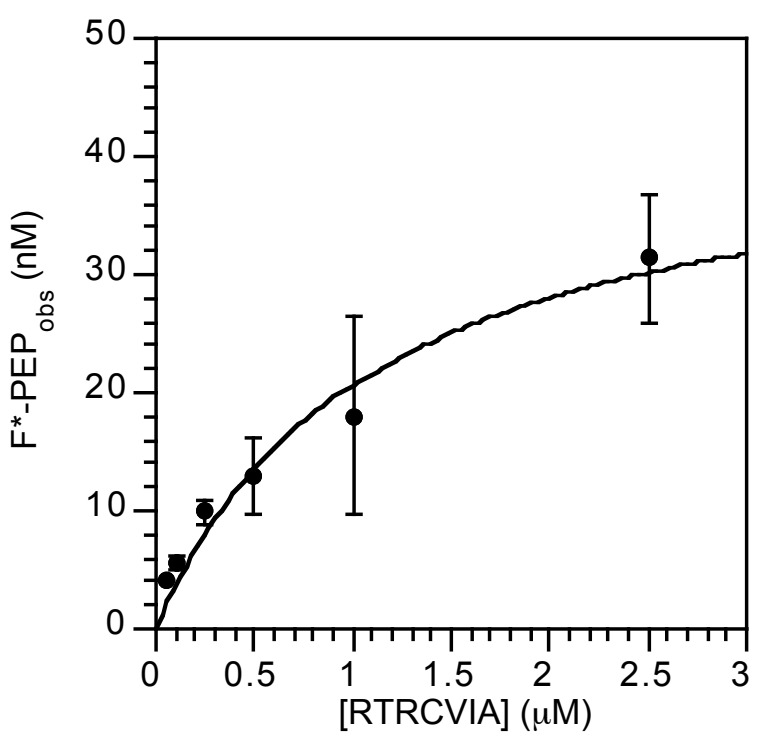

Figure S3. Isotope trapping experiment of enzyme-bound FPP with peptide RTRCVIA. In the pulse solution, yPFTase- $\left[{ }^{3} \mathrm{H}\right]$-FPP complex was formed from yPFTase $(1.4 \mu \mathrm{M})$ and $\left[{ }^{3} \mathrm{H}\right]-\mathrm{FPP}(200 \mathrm{nM})$. The pre-incubated binary complex was then mixed with a chase solution consisting of RTRCVIA (0.1-5 $\mu \mathrm{M})$ and unlabeled FPP $(70 \mu \mathrm{M})$. All the data points were an average of two and were fit to Equation $\mathrm{S} 1$ using a nonlinear regression program to determine $\left[E \cdot F P P_{0}\right]=43.5 \mathrm{nM}$ and $K_{1 / 2}=1.1 \mu \mathrm{M}$.

Next, GPP was investigated for its commitment to catalysis using the same isotope trapping method. GPP is an alternative $y$ PFTase substrate with a lower binding affinity. ${ }^{5}$ Thus, it is expected to require higher concentrations of peptide substrate to convert the same amount of the $E \cdot S^{*}$ binary complex to product compared with FPP. Being a better trapping substrate, FPP was used in the chase solution. The concentrations of enzyme and labeled substrate used in the pulse solution were three times and 50 times higher, respectively, than what was used in experiments with FPP to allow measurable amounts of geranylated peptide to be trapped and quantified. Fitting of the collected data points to Equation S1 provides $K_{1 / 2}=37.2 \mu \mathrm{M}$ and $\left[E \cdot G P P_{0}\right]=60.2 \mathrm{nM}$ (Figure S4). Using Equation S2 and the values of $K_{M}$ for GPP determined earlier (Table S1), a value of $\mathrm{c}_{f}$ was calculated to be 0.059 . That value is considerably smaller than that of FPP $\left(c_{f}=0.38\right)$. 


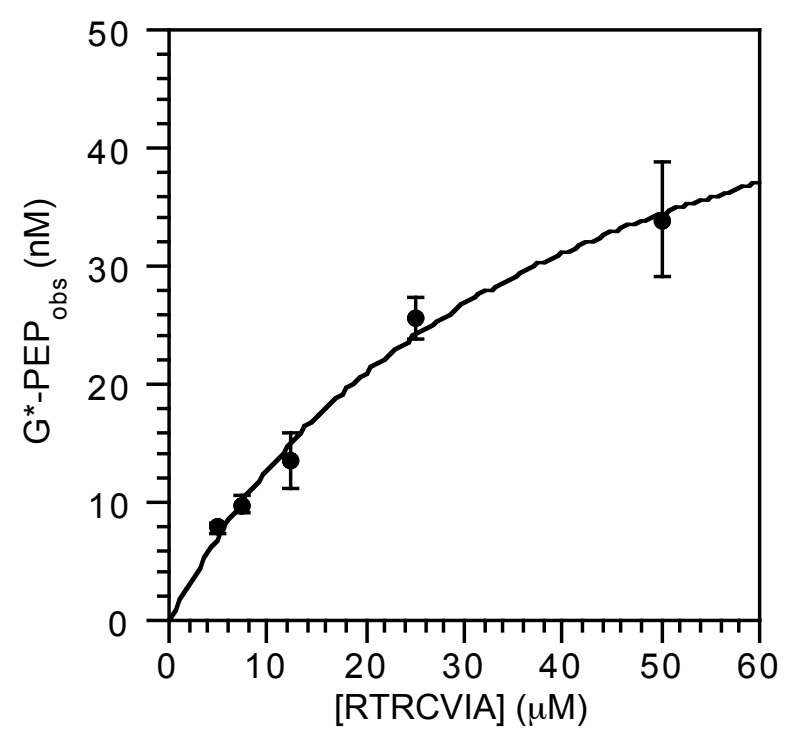

Figure S4. Isotope trapping experiment of enzyme-bound GPP with peptide RTRCVIA. In the pulse solution, the $y$ PFTase- $\left[{ }^{3} \mathrm{H}\right]-\mathrm{GPP}$ complex was formed from $y$ PFTase $(4.2 \mu \mathrm{M})$ and $\left[{ }^{3} \mathrm{H}\right]-\mathrm{GPP}(10 \mu \mathrm{M})$. The enzyme-bound FPP complex was then mixed with a chase solution consisting of RTRCVIA (10$100 \mu \mathrm{M})$ and unlabeled FPP $(70 \mu \mathrm{M})$. All the data points were an average of two or four values and were fit to Equation $\mathrm{S} 1$ using a nonlinear regression program to determine $\left[E \cdot G P P_{0}\right]=60.2 \mathrm{nM}$ and $K_{1 / 2}$ $=37.4 \mu \mathrm{M}$.

Comparison of Commitment to Catalysis for FPP and GPP and Effects on KIEs. Pompliano et al. have described the natural substrate of PFTase, FPP, as a "sticky" substrate due to its high binding affinity. ${ }^{6}$ FPP shows a high forward commitment to catalysis $\left(\mathrm{c}_{f}=0.38\right)$. In contrast, GPP has a significantly smaller $\mathrm{c}_{f}$ value of 0.059 , indicating that no significant masking of the intrinsic KIE for GPP occurs. Given that the enzyme binding affinity of GPP has been determined to be significantly lower (larger $K_{M A}$ ) than that of FPP, the experimental data from isotope trapping studies is consistent with the calculated substrate affinity in steady-state kinetic analysis. Finally, the $\mathrm{c}_{f}$ values determined above can be used to calculate the intrinsic isotope effects from the experimentally measured values using Equation S3 although the correction is minor since $c_{\mathrm{f}}$ for GPP is itself small. It should be noted that the $\mathrm{K}_{\mathrm{M}}$ values for $N$-Dansyl-GCVIA $(1.5 \mu \mathrm{M}$, used for the KIE experiments reported in this manuscript) and the corresponding value for RTRCVIA (3.5 $\mu \mathrm{M}$, used for the isotope trapping experiments described here) are similar suggesting that these two peptides have comparable affinities. ${ }^{7}$ Thus, it is likely that the cf value for $N$-Dansyl-GCVIA is comparable to that determined for RTRCVIA.

$$
{ }^{13 C}(V / K)=\frac{k_{12 C} / k_{13 C}+c_{f}}{1+c_{f}}
$$

\begin{tabular}{llll}
\hline & $K_{M}$ & $K_{1 / 2}$ & $c_{f}$ \\
\hline GPP & $2.19 \mu \mathrm{M}$ & $37.4 \mu \mathrm{M}$ & 0.059 \\
FPP & $420 \mathrm{nM}$ & $1.1 \mu \mathrm{M}$ & 0.38 \\
\hline
\end{tabular}

Table S1. Summary of kinetic, isotope trapping and commitment factor analysis. 


\section{Enzymatic Reactions and KIE Determination}

GPP solutions. Stock solutions of isotopically labeled and unlabeled GPP were prepared by dissolving the solids in a mixture of $1: 1$ water methanol mixture containing $\mathrm{NH}_{4} \mathrm{OH}(50 \mathrm{mM})$. The concentrations of the resulting solutions were measured by phosphate analysis and combined to prepare an equimolar solution of the two components. The ratio of the isotopomers was measured using mass spectroscopy.

Enzymatic reactions. To insure complete reduction of the cysteine residue in the peptide, $N$ Dansyl-GCVIA $(25 \mu \mathrm{L}, 390 \mu \mathrm{M})$ and DTT $(50 \mu \mathrm{L}, 500 \mathrm{mM})$ were mixed and incubated for $30 \mathrm{~min}$ at rt. Enzymatic reactions contained $N$-Dansyl-GCVIA $(1.95 \mu \mathrm{M})$, DTT $(5.0 \mathrm{mM}), \operatorname{MgCl} 2(5.0 \mathrm{mM})$, $\mathrm{ZnCl} 2(50 \mu \mathrm{M})$, Tris $\bullet \mathrm{HCl}(\mathrm{pH} 7.5,200 \mathrm{mM})$, GPP (partial conversion reactions: $100 \mu \mathrm{M}$; total conversion reactions: $0.8 \mu \mathrm{M}$ ) at the concentrations indicated in a total volume of $5.0 \mathrm{~mL}$. Enzyme (yPFTase, $2.0 \mu \mathrm{L}$ ) was added to the above solutions, mixed by vortexing, and the reactions allowed to proceed at $30^{\circ} \mathrm{C}$ for $48 \mathrm{~h}$. Each reaction (partial and total conversion) was performed in triplicate on the same day and was repeated three times. Thus, a total of 9 partial conversion and 9 total conversion reactions were used in the subsequent analysis of the ${ }^{13} \mathrm{C} \mathrm{KIE}$.

Product purification. Completed reactions were cooled to $\mathrm{rt}$ and fractionated using a Sep-Pak $\mathrm{C}_{18}$ reversed-phase cartridge to obtain the purified geranylated peptide product. Prior to application of the reaction mixture, the cartridge was washed with $10 \mathrm{~mL}$ Solvent $\mathrm{B}\left(\mathrm{CH}_{3} \mathrm{CN} / 0.1 \% \mathrm{TFA}\right.$, v/v) and equilibrated with $20 \mathrm{~mL}$ Solvent $\mathrm{A}\left(\mathrm{H}_{2} \mathrm{O} / 0.1 \% \mathrm{TFA}\right.$, v/v). The reaction mixture $(5.0 \mathrm{~mL})$ was then applied followed by washing with $10 \mathrm{~mL}$ Solvent A and then $10 \mathrm{~mL}$ of a 4:1 mixture of Solvents A and B. The desired product was eluted using $10 \mathrm{~mL}$ of a 1:9 mixture of Solvents A and B. The intense green fluorescence characteristic of the product in this last fraction was clearly visible. That fraction was lyophilized and stored at $-80^{\circ} \mathrm{C}$ for subsequent analysis.

ESI-MS Analysis of the Enzymatic Product. The geranylated peptide product was dissolved in $300 \mu \mathrm{L}$ of $\left(70: 30: 0.1, \mathrm{CH}_{3} \mathrm{CN} / \mathrm{H}_{2} \mathrm{O} / 0.1 \% \mathrm{HCO}_{2} \mathrm{H}, \mathrm{v} / \mathrm{v} / \mathrm{v}\right)$ and infused into a mass spectrometer at a flow

rate $5 \mu \mathrm{L} / \mathrm{min}$. Mass spectral data using an electrospray ion trap instrument (Thermo Electron Corporation) was acquired for the $[\mathrm{M}+\mathrm{Na}]^{+}$ion from the geranylated peptide product $(\mathrm{m} / \mathrm{z}=853.4)$ in the zoom scan mode in the $\mathrm{m} / \mathrm{z}$ range $850-860$ for 10 min per sample. Each mass unit was represented by 200 data points. The resulting spectra were exported into Microsoft Excel for subsequent analysis.

The area within \pm 0.5 mass units from peak $[\mathrm{M}+\mathrm{Na}]^{+}$and $\left[\mathrm{M}^{*} \cdot \mathrm{Na}\right]^{+}$peaks (where $\mathrm{M}^{*}$ is the ${ }^{13} \mathrm{C}$ labeled analogue) was fit to a sum of a baseline and two Gaussian peaks (each representing one isotopomer). The width and height of the peak from the fitted data were used to evaluate the peak area. Peak area of the labeled isotopomer overlaps with the peak of heavier non-labeled isotopomers. This masks the KIE and leads to observation of a lower KIE. The area of heavier non-labeled isotopomers (that exist due to presence of heavier isotopes in the non-labeled sample at natural abundance) was predicted and subtracted to correct the possible systematic error. That error, however, does not exceed $0.5 \%$.

\section{Transition State Calculations}

General. Computation was performed using Gaussian 03 software. A pure density functional theory (DFT) mpwpw91/6-31G(d) was employed in the computational analysis of the $\mathrm{S}_{\mathrm{N}} 1$ and $\mathrm{S}_{\mathrm{N}} 2$ model reactions. Solvation was included using a Polarized Continuum Model. A hybrid mpwpw91/6-31G(d) 
$\operatorname{Iop}(3 / 76=0594004060)$ level of theory in vacuum was used in the analysis of the reaction between GPP and ethyl thiolate.

For the starting materials a file containing coordinates was generated using Chem3D Ultra. The coordinates were used as an initial guess in a geometry optimization process. The geometry was optimized to a local minimum in case of starting materials and to a first order saddle point in the transition state calculations. The geometry optimization resulted in new a coordinate file of the compound and the new coordinates were used for the frequency computation. This calculation computes the vibrational frequencies and relative intensities. It also provides an accurate value of the $\Delta \mathrm{G}$ of the molecule.

Model $\mathbf{S}_{\mathrm{N}} 2$ reaction. The reaction of dimethylallyl chloride and triphenylphosphine was computed as follows. The models of dimethylallyl chloride and triphenylphosphine were generated in Chem3D Ultra and the structures were optimized in Gaussian 03. The coordinates of both starting materials were combined in the same file so that the $\mathrm{Cl}-\mathrm{C}-\mathrm{P}$ angle was close to $180^{\circ}$, and the $\mathrm{P}-\mathrm{C}$ and $\mathrm{C}-\mathrm{Cl}$ bonds were 1.3 times longer than normal (2.25 $\AA$ and $2.24 \AA$ respectively). The C-P bond was oriented along the three-fold symmetry axis of $\mathrm{PPh}_{3}$. The resulting molecule was optimized to a transition state. The $\Delta \mathrm{G}$ values of different isotopomers were computed for starting materials and the transition state. The Arrhenius equation was used to predict the rate of reaction as a function of isotopic substitution. The ratios of the rates of the reaction provided the KIE for a substituted position. The calculated ${ }^{13} \mathrm{C}$ KIEs for the $S_{N} 2$ model reaction between dimethylallyl chloride and triphenylphosphine are shown in Figure S5.

Model $\mathbf{S}_{\mathrm{N}} \mathbf{1}$ reaction. Attempts to find a transition state in a heterolytic dissociation of the $\mathrm{C}-\mathrm{Cl}$ bond in dimethylallyl chloride did not provide a reasonable TS. Thus, migration of chloride anion from dimethylallyl chloride to a dimethylallyl cation was used to model the KIEs in the $S_{N} 1$ reaction. Interestingly, the transition state structure is assymetrical. Thus, there are two sets of KIEs available for this reaction (a set if KIEs for tighter and looser attached prenyl group). The calculated ${ }^{13} \mathrm{C}$ KIEs for this $\mathrm{S}_{\mathrm{N}} 1$ model reaction with dimethylallyl chloride are shown in Figure S5.
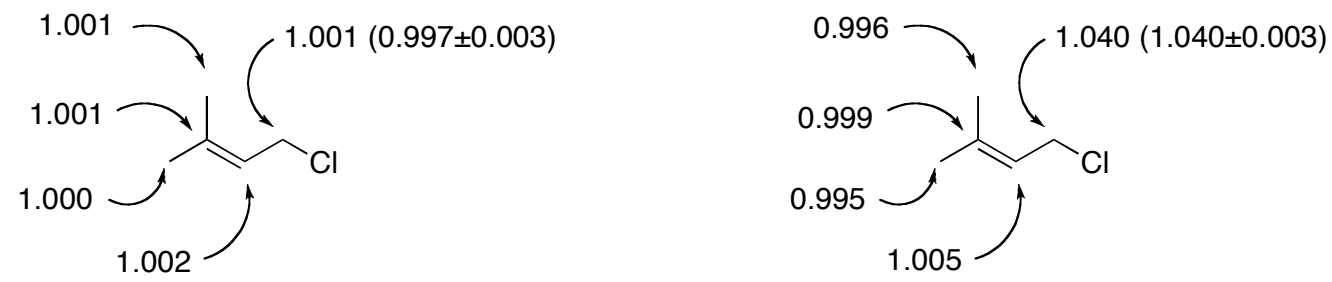

Figure S5. Calculated ${ }^{13} \mathrm{C}$ KIEs for model $\mathrm{S}_{\mathrm{N}} 1$ and $\mathrm{S}_{\mathrm{N}} 2$ reactions involving dimethylallyl chloride. Values in parentheses are the experimentally determined KIEs measured via ${ }^{13} \mathrm{C}$ NMR.

Enzymatic studies. Ethyl thiolate (anion) and geranyl diphosphate (neutral) were used as starting materials. GPP would protonate ethyl thiolate in solution, but there is evidence of numerous hydrogen bonds between the diphosphate group and various enzyme-derived residues in the PFTase ternary complex crystal structure thus such a model appears reasonable. First, the reaction between geranyl diphosphate and ethyl thiolate was modeled. The structures of the starting materials were optimized separately using the same hybrid approach mpwpw91/6-31G(d) Iop(3/76=0594004060) noted above. The TS was constructed using the optimized coordinates of the starting materials. The Gibbs energies of the starting materials and TS were calculated for different isotopomers and the expected KIEs were calculated using the Arrhenius equation. 
Bond length adjustment and TS structure determination. The lengths of $\mathrm{C}-\mathrm{O}$ and $\mathrm{C}-\mathrm{S}$ bonds in the calculated TS of the GPP/ethyl thiolate reaction were adjusted independently. The C-O bond length was adjusted by $-0.4,-0.2,-0.1,0.0,0.1,0.2,0.4,0.8,1.3,1.9 \AA$ Arelative to the TS; the C-S bond length was adjusted by $-0.6,-0.4,-0.3,-0.2,0.0,0.2,0.4,0.7,1.1,1.6 \AA$. As a result a total of $(10 * 10)-1=99$ new structures were generated. The optimization with key bonds fixed led to 47 chemically meaningful results (the rest of the structures were optimized to a wrong minimum; often the nucleophile would deprotonate the starting material). The frequencies and energies of key structures were computed. The carbon and deuterium KIEs for $\mathrm{S}_{\mathrm{N}} 2$ like transition states were computed.

Plots of the calculated ${ }^{13} \mathrm{C}$ KIE or ${ }^{2} \mathrm{H}$ KIEs versus C-O and C-S bond lengths are shown in Figure S6 (Left and Right panels, respectively). The contours from those data that match the experimentally measured ${ }^{13} \mathrm{C}$ KIE and ${ }^{2} \mathrm{H}_{2}$ KIE are shown in the central panel in Figure S6. The TS for the enzymecatalyzed reaction is given by the region of overlap. The experimental results reported here suggest a $\mathrm{C}$ $\mathrm{O}$ (leaving group) bond length of $1.69 \AA$ and a C-S bond length of $3.70 \AA$ in the TS. This TS can be thought of as being associative since it involves some participation of the nucleophile. However, it should be noted that other definitions of the term associative TS exist. ${ }^{8}$ The structures of the TS for the nonenzymatic GPP/ethyl thiolate reaction and the corresponding enzymatic reaction are shown in Figure S7.
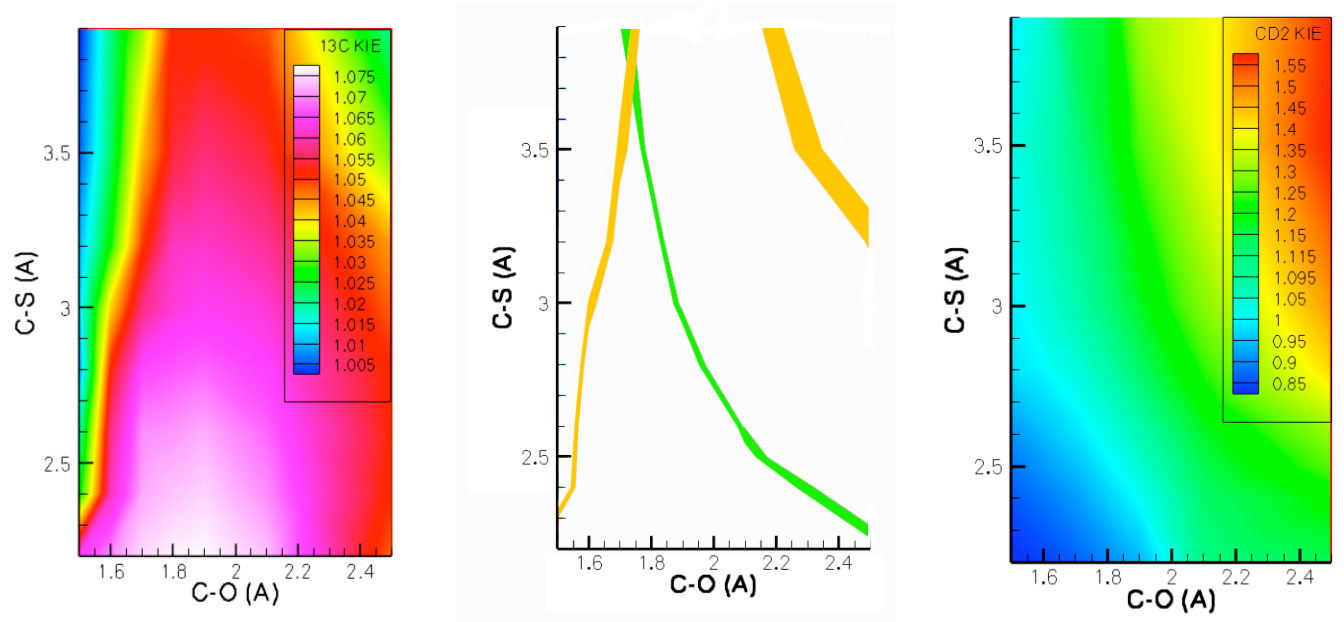

Figure S6. 3D Contour plots of KIEs versus C-O and C-S bond lengths. Left panel: Plot of calculated primary $\left[1-{ }^{13} \mathrm{C}\right] \mathrm{KIE}$ (z-axis, color contours) versus $\mathrm{C}-\mathrm{O}$ (x-axis) and $\mathrm{C}-\mathrm{S}$ (y-axis) bond lengths. Right panel: Plot of calculated secondary $\left[1-^{2} \mathrm{H}\right]_{2}$ KIE (z-axis, color contours) versus C-O (x-axis) and C-S (yaxis) bond lengths. Center panel: Superposition of calculated contours from Left and Right panels that match the experimentally determined values of the $\left[1{ }^{13} \mathrm{C}\right] \mathrm{KIE}$ (orange) and $\left[1-{ }^{2} \mathrm{H}\right]_{2} \mathrm{KIE}$ (green). The region of intersection gives the $\mathrm{C}-\mathrm{O}$ and $\mathrm{C}-\mathrm{S}$ bond lengths in the TS. 


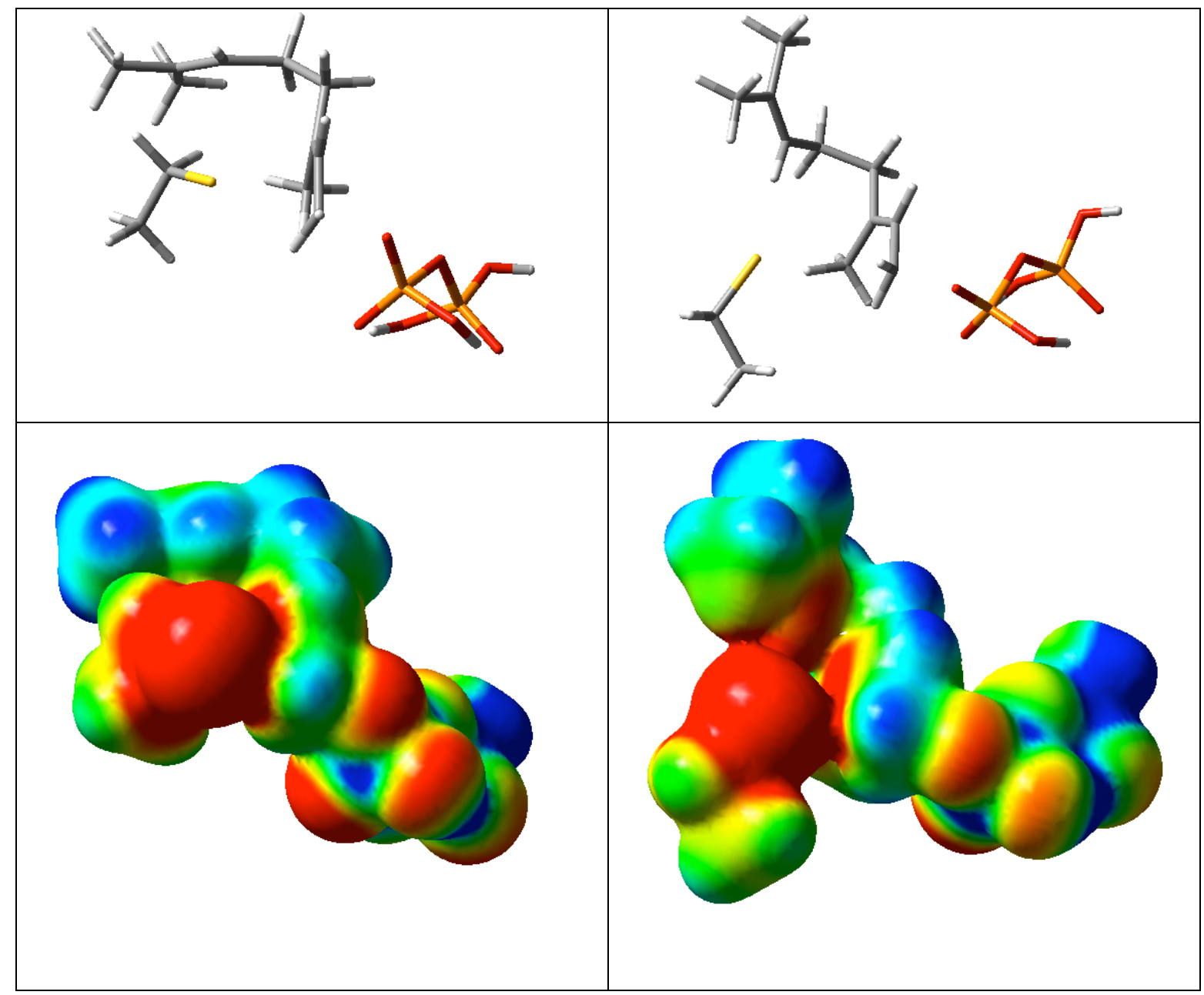

Figure S7. Transition state structures for nonenzymatic reaction between GPP and ethane thiolate and the corresponding enzyme catalyzed reaction. TS structures were modeled in the gas phase at the $m$ PW1N/6-31G* level of theory. Left panels are for the nonenzymatic reaction whereas the right panels are for the enzymatic process. Upper panels are stick representations while the lower panels represent the electrostatic potentials of those structures displayed in the upper panels (in the same orientation). Red represents more negative potential (-0.15 au), blue represents less negative potential ( $-0.05 \mathrm{au})$ and green is intermediate $(-0.10 \mathrm{au})$. The electrostatic potentials are presented mapped on the $0.005 \mathrm{au}$ isodensity surface. 


\section{References}

(1) Shao, Y.; Eummer, J. T.; Gibbs, R. A., Org. Lett. 1999, 1, 627-630.

(2) Hosokawa, A. M.S. Thesis, University of Minnesota, Minneapolis, 2006.

(3) Mathis, J. R.; Poulter, C. D., Biochemistry 1997, 36, 6367-76.

(4) Cleland, W. W., Biochemistry 1975, 14, 3220-4.

(5) Hsieh, S.-A. J. M.S., University of Minnesota, Minneapolis, 2002.

(6) Pompliano, D. L.; Schaber, M. D.; Mosser, S. D.; Omer, C. A.; Shafer, J. A.; Gibbs, J. B., Biochemistry 1993, 32.

(7) Mathis, J. R.; Poulter, C. D., Biochemistry 1997, 36, 6367-6376.

(8) O'Brien, P. J.; Herschlag, D., Biochemistry 2004, 41, 3207-3225. 